\title{
HIGH SPEED MODULATION AND CW OPERATION OF AlGaAs/GaAs LASERS ON Si
}

\author{
H.Z.Chen, J.Paslaski, A.Ghaffari, H.Wang, H.Morkoc, A.Yariv
}

California Institute of Technology

Pasadena, CA 91125

\begin{abstract}
Microwave modulation and $\mathrm{CW}$ operation of $\mathrm{AlGaAs}$ lasers grown by $\mathrm{MBE}$ on Si substrates have been obtained for the first time. Ridge waveguide lasers $(10 \mu \mathrm{m} \times 380 \mu \mathrm{m})$ were modulated with a microwave signal up to $2.5 \mathrm{GHz}$ which is notable considering the structure used. Near and far field measurements indicated a single transverse mode and a narrow beam angle $\left(4.8^{\circ}\right)$. Finally, polarization measurements appear to show the solely TE nature of the emission.
\end{abstract}

\section{INTRODUCTION}

Successful monolithic integration of high speed AlGaAs laser diodes with high density Si VLSI on a single chip can provide numerous opportunities to fully utilize merits of both Si and GaAs technologies.[1] Such an integration requires very high quality AlGaAs material grown on $\mathrm{Si}$ substrates for continuous low power and high speed operations. Over the years, significant progress has been made [2] to improve the epitaxial growth of GaAs on $\mathrm{Si}$ by MBE. However, in most AlGaAs lasers grown on $\mathrm{Si}$ so far, threshold current densities have been very high (around $3 \mathrm{kA} / \mathrm{cm}^{2}$ )[3-6] and $\mathrm{CW}$ operation has not been achieved. In this paper, we report the first CW operation of AlGaAs on Si broad area lasers with an extremely low threshold current density, along with the first high speed modulation of GaAs on Si lasers. In addition an investigation of the spatial modes and the light polarization of ridge waveguide lasers will be discussed.

\section{MBE GROWTH OF GaAs ON Si}

Substrate preparation is one of the most crucial steps in the epitaxy of GaAs on Si. The difficulties associated with the removal of rather stable $\mathrm{SiO}_{2}$ on $\mathrm{Si}$ (which forms the backbone of the $\mathrm{Si}$ industry) presented a formidable obstacle until the development of volatile oxides which can be grown during the chemical preparation of $\mathrm{Si}$. This volatile oxide can then be easily desorbed in an MBE system before growth leaving an atomically clean surface. Several of the procedures are detailed in Ref.7, and that followed in this work is patterned after the one developed by F.Allen and his students and described elsewhere in detail.\{1] This particular cleaning procedure consists of degreasing, removal of heavy metals and a series of oxide growth and stripping steps followed by a last oxide growth in a $\mathrm{HCl}: \mathrm{H}_{2} \mathrm{O}_{2}: \mathrm{H}_{2} \mathrm{O}$ solution. The final volatile oxide is desorbed in the MBE system by heating the substrate up to about $1000^{\circ}$ for 2 minutes. The growth however is initiated at substrate temperatures between 200 and $400{ }^{\circ} \mathrm{C}$ depending on whether the initial deposit is of $\mathrm{As}_{4}$, $\mathrm{As}_{2}$ or $\mathrm{Ga}$. In order to obtain high crystalline quality, the growth rate is kept low for the first 200-250 $\dot{A}$, after which it is increased to the nominal $1 \mu \mathrm{m} /$ hour rate and the substrate temperature is raised to $580^{\circ} \mathrm{C}$. After the $2 \mu \mathrm{m} \mathrm{GaAs}$ buffer layer is completed, the substrate temperature is raised to $700^{\circ} \mathrm{C}$ and other growth parameters are so adjusted.

The structures were fabricated into broad area and ridge waveguide stripe lasers with widths of $120 \mu \mathrm{m}$ for broad area and $10 \mu \mathrm{m}$ for ridge respectively. Ohmic contacts were made to the $\mathrm{p}^{+} \mathrm{GaAs}$ and the back side of the Si substrate. The substrate was then lapped down to about $75 \mu \mathrm{m}$ since GaAs and Si cleave in different orientations ([100] for GaAs and [111] for Si). The threshold current density was measured using broad area lasers while the stripe lasers were used for the study of near and far field patterns, high speed modulation, and polarization.

\section{CW OPERATION OF BROAD AREA LASERS}

Continuous wave operation of GaAs on Si lasers is considered important for obvious applications reasons as well as establishing the quality of the highly mismatched composite material system. In this work, threshold current densities as low as $214 \mathrm{~A} / \mathrm{cm}^{2}$ in devices with cavity lengths of $1900 \mu \mathrm{m}$ were measured[8] which compare very favorably with those that are obtained with GaAs substrates in many laboratories. It should be pointed out however that we have recently obtained threshold current densities of about $90 \mathrm{~A} / \mathrm{cm}^{2}$ for lasers on GaAs substrates (Fig.1) [9]. Nevertheless the attention must now be focused on lifetime and other properties, especially the high speed modulation characteristics. Such low threshold densities have allowed the operation of even broad area devices $(980 \mu \mathrm{m}$ $\times 120 \mu \mathrm{m}$ ) continuously at room temperature. The CW threshold of this particular laser was $350 \mathrm{~mA}$ corresponding to a threshold current density of $298 \mathrm{~A} / \mathrm{cm}^{2}$ which is respectable. In addition, output power levels as high as $270 \mathrm{~mW} /$ facet were also obtained under pulsed conditions. 
The data reported here represent a considerable improvment over previously reported current densities.[3-6]

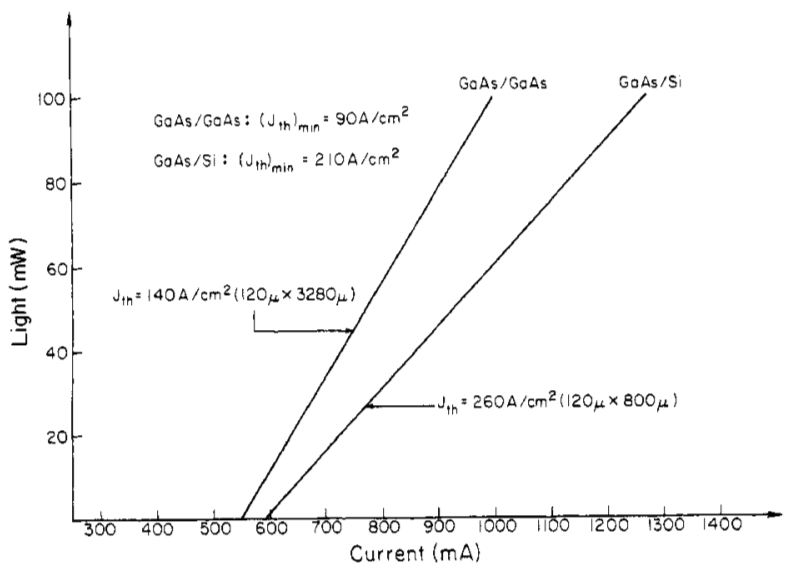

Fig.1 Comparison of the threshold current densities of GaAs on Si and GaAs on GaAs SQW GRINSCH lasers.

\section{RIDGE-WAVEGUIDE STRIPE LASERS}

In an effort to investigate the near and far field patterns of radiation, the polarization of lasing modes, and high speed modulation characteristics, ridge-waveguide stripe geometry lasers were fabricated. The ridges used in this study have a height of $1.0-1.5 \mu \mathrm{m}, 0.3-0.5 \mu \mathrm{m}$ from the quantum well, and a top width of $10 \mu \mathrm{m}$. Silicon dioxide was subsequently deposited on the patterned wafer, and windows were opened on the ridge to make ohmic contact to the $\mathrm{p}^{+}$GaAs cap layer with $\mathrm{Cr} / \mathrm{Au}$ by a lift-off. The wafer was then annealed at $400^{\circ} \mathrm{C}$ for 5 minutes, and lapped down to about $75 \mu \mathrm{m}$ thick. AuGe/Au was finally evaporated on the Si to complete the fabrication. The stripe lasers had threshold currents ranging from $50 \mathrm{~mA}$ to $150 \mathrm{~mA}$ depending on the quality of the facets. Peak output of $60 \mathrm{~mW}$ and an external quantum efficiency of $87 \%$ have been obtained.

\section{NEAR AND FAR FIELD PATTERNS}

Near and far field patterns can provide valuble data with respect to the spatial modes in the laser. It is well known that filamentation causes instabilities in the device performance which is undesired. Fig.2 shows the near field of a typical ridge laser, which clearly demonstrates good current guiding in the lateral direction, and a single lasing filament. A plot of light vs. current also showed no signs of kinks typically caused by mode hopping. Fig.3 shows the far field pattern of a ridge laser; a very narrow, single lobed far field beam was observed. The achieved beam angle of $4.8^{\circ}$ compares very well to that of typical GaAs on GaAs stripe lasers.

\section{POLARIZATION OF LIGHT OUTPUT}

It has been suggested that the polarization of light in GaAs on Si lasers consists of both TE and TM modes due to strain induced by the residual thermal mismatch. To investigate this speculation, we chose two lasers with

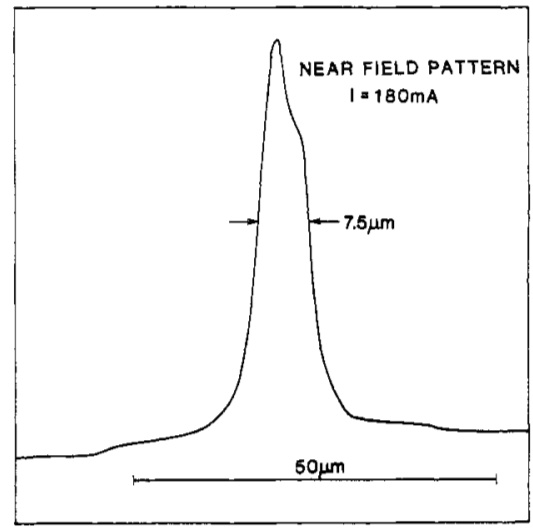

Fig.2 Near field pattern of the ridge waveguide stripe laser.

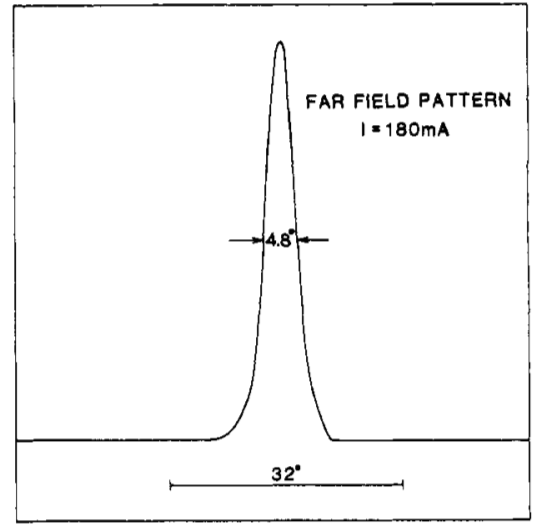

Fig.3 Far field pattern of the ridge waveguide stripe laser.

surface cracks perpendicular and parallel to the ridgewaveguide. A polarization selective measurement of lasing spectrum did not confirm the existence of any TM modes. However, this study shed some light on the apparent effect of strain on mode selection. In the laser with surface cracks perpendicular to the ridge-waveguide, shown in Fig.4, the spectral lines were centered around $8700 \AA(1.425 \mathrm{eV})$, much like typical GaAs on GaAs lasers with the exception of some very weak modes at higher energy around $1.48 \mathrm{eV}$. In the laser with cracks parallel to the ridge (not through it), shown in Fig.5, the spectrum was much different and consisted of lines of comparable strength centered around $1.424 \mathrm{eV}$ and $1.48 \mathrm{eV}$. All of these modes were $\mathrm{TE}$ polarized and we did not observe any TM modes. We attribute the observed difference in the lasing spectrum to the effect of strain in the two lasers.

\section{HIGH SPEED MODULATION}

A ridge waveguide lasers with dimensions of $10 \mu \mathrm{m} \times 380 \mu \mathrm{m}$ was used to study frequency response. The laser was mounted in a microwave package, and DC bias and microwave signal were then applied through a bias-T. Frequency response was measured by detection with a high speed $P I N$ photodiode and is shown in Fig.6. This curve, 


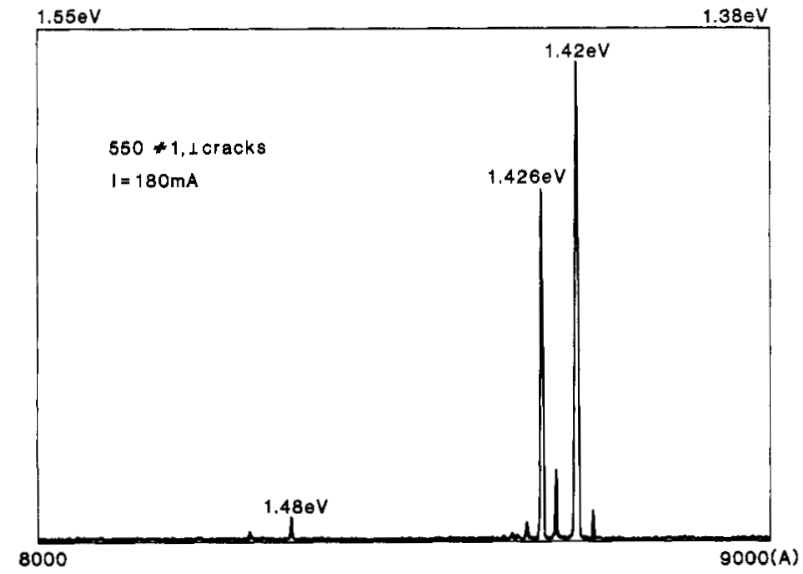

Fig.4 Lasing spectrum with cracks $\perp$ and going through the ridge waveguide.

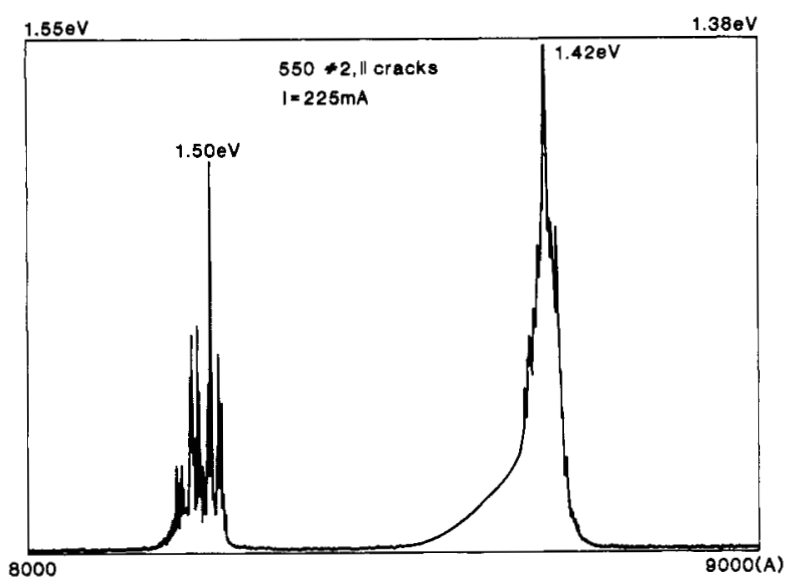

Fig.5 Lasing spectrum with cracks \| and not going through the ridge waveguide.

taken under high bias condition, had the highest corner frequency obtained which was about $2.5 \mathrm{GHz}$. This result is the first high speed measurement in this material system and is extraordinary in that comparable devices on GaAs substrates have bandwidth limitations of $1-2 \mathrm{GHz}$. Only specialized structures such as buried heterostructure short cavity lasers on semi-insulating substrates specifically designed for high speed modulation have achieved modulation bandwidths above $10 \mathrm{GHz}$. The lasers we used however are gain guided by the lateral current confinement and no attempt was made to achieve index guiding. By optimizing laser structures much higher corner frequencies are expected. Our preliminary results clearly show the potential of GaAs on Si lasers for optical interchip communication.

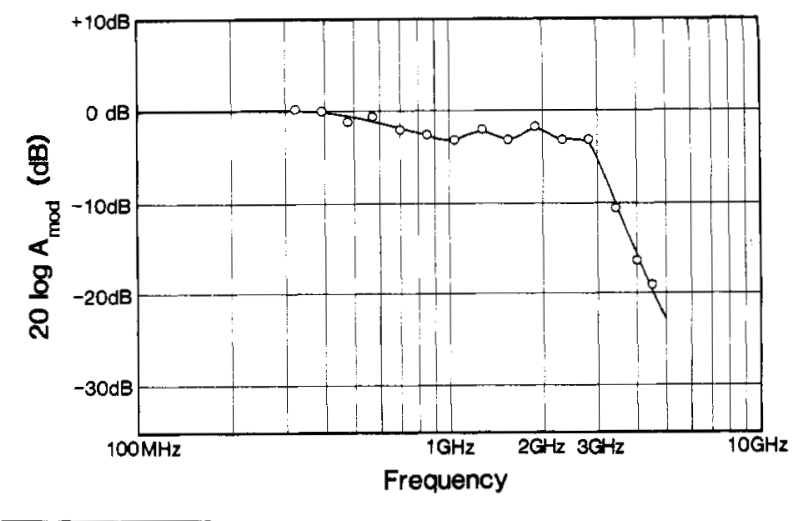

Fig.6 Frequency response of a $10 \mu \mathrm{m} \times 380 \mu \mathrm{m}$ ridge waveguide laser.

\section{CONCLUSIONS}

We have shown that the material quality of AlGaAs heterostructures on $\mathrm{Si}$, despite the $4 \%$ lattice mismatch and large thermal mismatch, has been improved to the point that room temparature $\mathrm{CW}$ operation even in broad area devices is possible. The threshold current densities on $\mathrm{Si}$ substrates are now comparable to those obtained in many laboratories on GaAs substrates. High speed modulation using gain guided lasers showed a corner frequency of $2.5 \mathrm{GHz}$ which is expected to improve with optimized index guided structures. Even the present results point to the potential of this composite technology in optical interconnects for Si VLSI.

\section{ACKNOWLEDGEMENT}

This work is supported by Office of Naval Research, Air Force Office of Scientific Research and the National Science Foundation. One of us, H.M. is also a distinguished visiting scientist at Caltech Jet Propulsion Laboratory and is supported partially by SDIO-IST.

\section{REFERENCES}

(1) R.Houdré andH.Morkoç, to appear in CRC Critical Review.

(2) W.T.Masselink, R.Fischer, J.Klem,T.Henderson, H.Morkoc,, J.Vac.Sci.Technol.1985,B3,pp.548.

(3) H.Chong and C.Fonstad,Appl.Phys.Lett.,1987, 51,pp.221

(4) J.P.van der Ziel,R.Dupuis,R.A.Logan,R.M.Mikulyak, C.J.Pinzone, and A.Savage, Appl.Phys.Lett.,1987,50 ,pp.454

(5) S.Sakai, T.Soga, M.Takeyasu, and M.Umeno, Jpn.J.Appl.Phys.,1985,24,pp.L666 
(6) R.Fisher, W.Kopp, H.Morkoc, M.pion, A.Specht, G.Burkhart, H.Appelman, D.McGougan and R.Rice, Appl.Phys.Lett.,1986, 48, pp.1360

(7) R.C.Henderson, A.Ishzeka and Y.Shiraki,

J.Electrochem.Soc,1972, 119,pp.772, ibid, 1986,133, pp.666

(8) H.Z.Chen, A.Ghaffari,H.Wang,H.Morkoc, A.Yariv,

Optics Letters, 1987, 12, No.10

(9) H.Z.Chen, A.Ghaffari, H.Morkoc, A.Yariv, Appl.Phys.Lett., in print. 